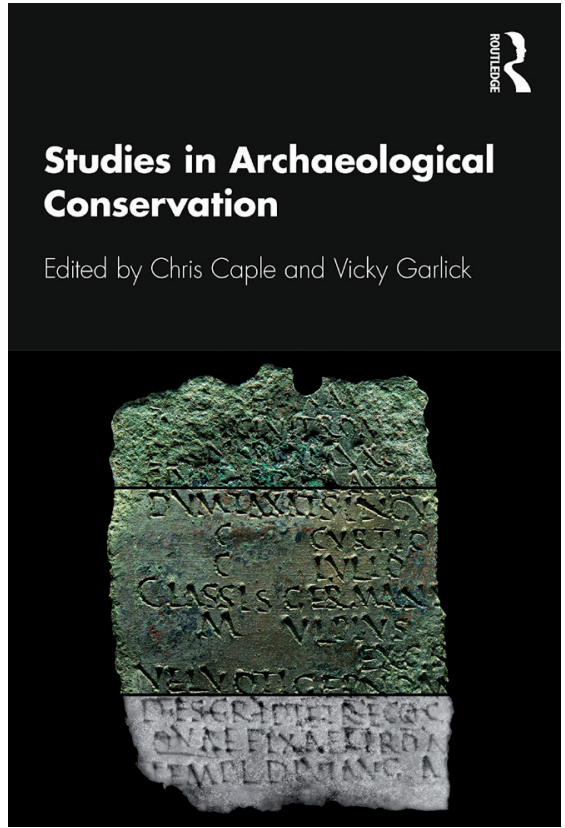

Studies in Archaeological Conservation es un libro compuesto por casos prácticos sobre conservación y restauración arqueológica, recopilados por Chris Caple y Vicky Garlick. Los autores pertenecen a la Universidad de Durham, en Reino Unido, país al que se encuentran asociados la mayoría de los autores que contribuyen a la obra. Se presenta como un libro destinado a estudiantes y profesionales de la conservación y restauración, y también a profesionales de la arqueología.

C. Caple empieza el libro con un discurso sobre la "naturaleza de los artefactos arqueológicos" y sobre los objetivos y criterios de procedimientos básicos, entre otros, la limpieza o la estabilización. En este capítulo introductorio, el autor relaciona las ideas que plasma con referencias a los diferentes capítulos que conforman la obra.

Siguen a la introducción veintiséis casos de estudio, cada uno con autoría propia, y agrupados en cinco categorías de materiales: piedra y yeso; cerámica y vidrio; metales; orgánicos (madera, textiles y cuero); hueso y composites. Todas estas categorías contemplan, a su vez, distintos materiales, cronologías y problemáticas diversas. Tan diversas, que también lo es el contenido.

La mayoría de los capítulos son casos prácticos de conservación y restauración, en general descripciones de intervenciones directas $y$, en menor medida, de trabajos exclusivamente de conservación preventiva. Frente a colecciones amplias, predominan los casos de piezas únicas, por ejemplo, el tratamiento de un plato de cristal de roca egipcio (Primera Dinastia, c. 3000 ) o el de un zapato de un naufragio del siglo VXIII. Todos ellos, aportan datos

\section{Studies in Archaeological Conservation}

\author{
Chris Caple y Vicky Garlick (editores)
}

Routletge, Londres, 2020.

Ebook ISBN: 9780429342257

290 páginas valiosos sobre la práctica de la conservación y restauración, a la vez que dan cuenta de la diversidad de casos que se pueden presentar en el registro arqueológico.

Sin embargo, hay algunos capítulos alejados del objetivo principal de la obra. Entre ellos, estudios meramente arqueológicos o históricos, que no presentan ni problemas, ni objetivos, ni métodos de conservación y restauración (capítulos 3, 7, 10 y 15). También se incluye el tratamiento de un fósil jurásico (capítulo 5), un espécimen objeto de estudio paleontológico, y no arqueológico. Si el significado de los objetos es relevante para las intervenciones de conservación y restauración, esta distinción también debería serlo.

Para quien espere un manual al uso, que ordene criterios y procedimientos de conservación y restauración, y con la excepción del capítulo de introducción, este no es el libro indicado. Tampoco son novedosos muchos de los enfoques y procedimientos recogidos en los casos de estudio de este libro. Pero lo cierto es que no parece el objetivo. Como declara C. Caple en la introducción, "frecuentemente la bibliografía se centra en nuevos descubrimientos presentados en conferencias o publicados en revistas; poco hay publicado sobre prácticas reales". Más bien, se podría añadir, que estas están muy dispersas y no siempre aglutinadas en un mismo volumen sobre conservación y restauración arqueológica.

Precisamente, uno de los valores de esta obra es que recoge numerosos trabajos que muestran los matices de los casos reales, difícilmente estandarizables, que no se pueden respaldar en trabajos previos salvo de manera 
fragmentaria, y con variantes que los acaban convirtiendo en casos únicos. Casos reales que, en definitiva, necesitan nutrirse de experiencias previas parecidas. Ciertamente, no es fácil encontrarlos recopilados, algo que facilita este nuevo libro.

Lucía López-Polín

Institut Català de Paleocologia Humana i Evolució Social (IPHES) / Dept. Història i Història de l'Art, Universitat

Rovira i Virgili

\section{() $\Theta \Theta$}

https://doi.org/10.37558/gec.v18i1.864 